\title{
APLIKASI RETENSI REKAM MEDIS MENGGUNAKAN MICROSOFT ACCESS
}

\author{
Alfauzain $^{1}$, Berly Nisa Srimayarti ${ }^{2}$, Dian Novita ${ }^{3}$, Muhammad Ridwan ${ }^{4}$ \\ Prodi S1 Administrasi Rumah Sakit ${ }^{1,2,3}$ Prodi D3 Rekam Medis ${ }^{4}$ \\ STIKES Dharma Landbouw Padang \\ al.stikesdl@gmail.com ${ }^{1}$, berlynisasrimayarti@gmail.com²,
}

\begin{abstract}
Medical record retention is a system that regulates the storage period for medical record files. Medical records officers are also involved in destroying medical records including in the retention process. The slow retention process resulted in a large number of medical record files piling up in storage racks so that the medical record space became narrow. Developing medical record retention applications using Microsoft Access. This research method is carried out by conducting a Literature Review with the Literature Study method. The data sources in this study were 3 articles by looking at the inclusion and exclusion categories. Analyze data in terms of similarities, inequalities, views, compare and summaries. The results of 3 literature study journals are medical record retention applications made with web-based methods and web-based imaging. The system design uses Flowmap, Data Flow Diagram (DFD) and Entity Relationship Diagram (ERD) and is implemented with the Microsoft Visual Basic.Net programming language and Microsoft Access as a Database Management System (DBMS). The medical record retention application is very helpful for officers in separating active and inactive medical record files, which are equipped with menus according to user needs. The conclusion that can be obtained is that the retention application design is made by various methods to determine the constraints that exist in the application, this is useful as an application development to minimize errors that occur in the retention process.
\end{abstract}

Keywords: Design, Effectiveness, Microsoft Access, Retention,

\begin{abstract}
ABSTRAK
Retensi rekam medis adalah sistem yang mengatur jangka waktu penyimpanan berkas rekam medis. Petugas rekam medis juga terlibat dalam melakukan pemusnahan rekam medis termasuk pada proses retensi. Lambatnya proses retensi mengakibatkan banyaknya berkas rekam medis yang tertumpuk di dalam rak penyimpanan sehingga rungan rekam medis menjadi sempit. Melakukan dan mengembangkan aplikasi retensi rekam medis menggunakan Microsoft Access. Metode penelitian ini dilakukan dengan melakukan Literatur Review dengan metode Studi Literatur. Sumber data dalam penelitian ini adalah 3 artikel dengan melihat kategori inklusi dan ekslusi. Analisa data dalam kesamaan, ketidaksamaan, pandangan, bandingkan dan ringkasan. Hasil dari 3 artikel studi literatur yaitu aplikasi retensi rekam medis yang dibuat denganmetode berbasis web dan juga imaging berbasis web. Perancangan sistem menggunakan Flowmap, Data Flow Diagram (DFD) dan Entity Relation Diagram (ERD) serta diimplementasikan dengan bahasa pemrograman Microsoft Visual Basic.Net dan Microsoft Access sebagai Database Management System (DBMS). Aplikasi retensi rekam medis sangat membantu petugas dalam memisahkan berkas rekam medis aktif dan inaktif yang dilengkapi dengan menu-menu yang sesuai dengan kebutuhan user. Kesimpulan yang di dapatkan yaitu perancangan aplikasi retensi dibuat dengan berbagai metode untuk mengetahui kendala yang terdapat pada aplikasi, hal ini berguna sebagai pengembangan aplikasi untuk meminimalisir kesalahan yang terjadi daam proses retensi.
\end{abstract}

Kata Kunci: Efektifitas, Microsoft Access, Retensi, Perancangan, 


\section{PENDAHULUAN}

Rumah sakit adalah salah satu sarana pelayanan kesehatan yang berorientasi kepada penyembuhan pasien, dimana dalam pengelolaan pelayanan kesehatan dan dalam menerima pasien di tempat penerimaan pasien. Upaya pemerintah dalam meningkatkan mutu pelayanan rumah sakit adalah dengan adanya program akreditasi, sehingga setiap rumah sakit berusaha memenuhi kriteria-kriteria akreditasi salah satunya adalah system pelayanan rekam medis. Sesuai Keputusan Menteri Kesehatan RI. No. 034/Birhub/1972, rumah sakit diwajibkan untuk menyelenggarakan rekam medis (Depkes RI, 2006) (Kemenkes RI, 2009).

Rekam medis adalah keterangan baik tertulis maupun yang terekam tentang identitas, anamnesa, pemeriksaan fisik, laboratorium, diagnosa serta segala pelayanan dan tindakan medis yang diberikan kepada pasien, dan pengobatan baik yang dirawat inap, rawat jalan, dan pelayanan gawat darurat. Pengertian secara sederhana bahwa rekam medis merupakan catatan dan dokumen yang berisikan tentang kondisi keadaan pasien, tetapi jika dikaji lebih mendalam rekam medis mempunyai makna yang lebih kompleks tidak hanya catatan biasa, karena didalam catatan tersebut sudah ada tercermin segala informasi yang menyangkut seorang pasien yang akan di jadikan dasar dalam menentukan tindakan yang lebih lanjut dalam upaya pelayanan maupun tindakan medis lainnya yang diberikan kepada seorang pasien (Depkes RI, 2006) .

Rekam medis bersifat rahasia artinya tidak semua orang yang bisa membaca dan mengetahuinya dalam pasal 10 ayat 1 Permenkes RI nomor 269/Menkes/III/2008 mengatakan bahwa informasi tentang identitas, diagnosa, riwayat penyakit, riwayat pemeriksaan, dan riwayat pengobatan pasien harus dijaga kerahasiaan oleh dokter, dokter gigi, tenaga kesehatan tertentu, petugas pengelola dan pimpinan saran pelayanan kesehatan (Permenkes RI, 2008) (Nina, 2018).

Salah satu bagian rekam medis yang menunjang pelayanan adalah ruang penyimpanan (filing) yang bertanggung jawab dalam proses pengelolaan dokumen rekam medis, dengan salah satu kegiatannya adalah melakukan pemusnahan dokumen rekam medis yang tidak memiliki nilai guna rekam medis dengan kategori tertentu dan nantinya dilakukan pemusnahan khususnya dokumen rekam medis yang tidak disimpan secara abadi (Rufiantum, 2007).

Pemusnahan rekam medis merupakan salah satu upaya yang dilakukan oleh pihak rumah sakit dengan tujuan mengurangi penumpukkan berkas rekam medis diruangan penyimpanan. Dokumen rekam medis yang akan dimusnahkan dengan kategori adanya kerusakan dokumen rekam medis selain itu dokumen rekam medis yang memiliki masa simpan lebih dari 5 tahun atau 2 tahun yang disebut dengan rekam medis in aktif sesuai standar Jadwal Retensi Arsip (JRA) pada masing-masing rumah sakit dan berdasarkan Surat Edaran Dirjen Pelayanan Medis No. HK.00.06.1.5.01160 tahun 1995 tentang Jadwal Retensi Arsip, sehingga dokumen tersebut perlu dimusnahkan (Pepres RI Nomor 11, 2008).

Berdasarkan surat edaran Dirjen Yanmed HK.00.06.1.5.0.1160 tahun 1995, Rekam medis aktif adalah rekam medis yang masih digunakan diterapkan di masing-masing rumah sakit. Sedangkan rekam medis in aktif adalah rekam medis dihitung sejak tanggal terakhir pasien tersebut berobat atau 5 (lima) tahun setelah pasien meninggal dunia. Salah satu proses dari pemusnahan berkas rekam medis yaitu retensi (penyusutan). Menurut (Saraswati, 2015) retensi adalah proseskegiatan memilih Dokumen Rekam Medis (DRM) untuk memisahkan DRM aktif dan DRM inaktif sesuai dengan jangka waktu penyimpanan DRM. Saat ini sudah banyak penyediaan pelayanan kesehatan yang memanfaatkan teknologi informasi guna 
menunjang dalam pemberian pelayanan kesehatan, untuk itu diperlukan perancangan aplikasi (program) yang dapat memudahkan dalam pelayanan kesehatan (Devita, 2015).

Perancangan adalah suatu kegiatan untuk merancang atau membuat dan mebentuk pola-pola tertentu baru yang dapat menyelesaikan masalah-masalah yang dihadapi perusahaan yang diperoleh dari pemilihan alternatif sistem yang terbaik. Perancangan mempunyai 2 maksud, yaitu untuk memenuhi kebutuhan kepada pemakai sistem dan untuk memberikan gambaran yang jelas kepada pemogram komputer dan ahli-ahli teknik lainnya yang terlibat (Mujiati, H., 2014).

Berdasarkan artikel yang penulis amati dengan judul Sistem Retensi Berkas Rekam Medis Terintegrasi Perancangan Sistem Informasi Berbasis Web di Klinik Pratama yang di tulis oleh Hendra Rohman dkk pada tahun 2019, dari hasil yang ditemukan klinik pratama belum pernah dilaksanakan proses retensi berkas rekam medis, terjadi penumpukan berkas rekam medis di ruangan penyimpanan serta petugas maupun dokter sulit menemukan berkas yang sudah inaktif bahkan berkas yang sudah lama sulit untuk dibaca karena rusak, untuk itu pihak klinik akan melakukan perancangan terhadap sistem retensi agar mempermudah dalam pemisahan berkas aktif dan inaktif dalam bentuk file hasil scan formulir rekam medis, hal ini sejalan dengan artikel yang berjudul pengembangan sistem informasi retensi rekam medis di rumah sakit dustira cimahi yang ditulis oleh Ardi Taryanto dan Lilis Nur Handayani, dengan hasil penelitian rumah sakit melakukan proses pendokumentasian data berkas rekam medis yang telah diretensi masih cara manual, yaitu dengan mengarsipkan kedalam buku yang disebut buku retensi. Hal ini mengakibatkan tidak efektif dan efisien jika ditemukan di kemudian hari. Untuk itu rumah sakit melakukan pembangunan terhadap aplikasi untuk membantu dalam mengarsipkan atau mendokumentasikan berkas rekam medis yang sudah di retensi yang menggunakan Visual Basic. Net 2010 dan database Management System/ DBMS Ms. Access (Rohman, Evanka, \& Ikhsani, 2019).

\section{METODE}

Jenis penelitian ini adalah penelitian studi literatur. Studi literatur adalah cara yang dipakai untuk menghimpun data-data atau sumber-sumber yang berhubungan dengan topik yang diangkat dalam penelitian. Sumber literature yang digunakan dalam penelitian ini melibatkan 3 artikel yang berasal dari jurnal. Keywords yang digunakan saat pencarian artikel adalah retensi AND rekam medis AND Microsoft Access.

Kriteria inklusi dari studi literatur sebagai berikut, Artikel yang terbit 6 tahun terakhir (2015-2020), Variabel penelitian (retensi rekam medis), Metode penelitian (pengembangan sistem). Kriteria eksklusi dari artikel studi literatur sebagai berikut: Jurnal tidak ada ISSN, Artikel yang berbayar atau tidak bisa di download secara full.

Berdasarkan keyword, kriteria inklusi, dan ekslusi di dapatkan 305 artikel. Namun, tidak semua yang sesuai, kemudian dilakukan filter secara manual maka di dapatkan sebanyak 3 artikel dan akan di telaah lebih lanjut, yaitu Rancangan Banguna Sistem Informasi Retensi Rekamm Medis dengan Metode Imaging Berbasis Web, Pengembangan Sistem Informasi Retensi Berkas Rekam Medis di Rumah Sakit Dustika Cihami, Sistem Retensi Berkas Rekam Medis Terintegrasi: Perancangan Sistem Informasi Berbasis Web di Klinik Pratama.

\section{HASIL}

Peneliti melakukan identifikasi pada 3 artikel yang memenuhi persyaratan untuk dilakukan analisis. Artikel tersebut berasal dari daerah Padang, Bandung, dan Pekanbaru. 2 artikel dianalisis, berdasarkan 
tujuan penelitian yaitu mengetahui elemen data dalam perancangan retensi rekam medis menggunakan microsoft access dan mengetahui rancangan aplikasi retensi rekam medis menggunakan microsoft access, dan 1 artikel dilihat dari efektivitas dari aplikasi retensi rekam medis. Berikut tabel 1. Hasil analisis telaah artikel.

Tabel 1. Hasil telaah Beberapa Artikel

\begin{tabular}{|c|c|c|c|c|}
\hline No & $\begin{array}{l}\text { Tujuan } \\
\text { Penelitian }\end{array}$ & Judul Peneliti & Peneliti & Hasil \\
\hline \multirow[t]{2}{*}{1} & $\begin{array}{l}\text { Mengetahui } \\
\text { elemen data } \\
\text { dalam } \\
\text { perancangan } \\
\text { retensi rekam } \\
\text { medis } \\
\text { menggunaka } \\
\text { n microsoft } \\
\text { access }\end{array}$ & $\begin{array}{l}\text { 1) Rancang Bangun } \\
\text { Sistem Informasi } \\
\text { Retensi Rekam } \\
\text { Medis Dengan } \\
\text { Metode Imaging } \\
\text { Berbasis Web } \\
\text { (Ahmad Junaidi, } \\
\text { 2019) }\end{array}$ & $\begin{array}{l}\text { Ahmad } \\
\text { Junaidi, } \\
\text { Khairul } \\
\text { Zaman }\end{array}$ & $\begin{array}{l}\text { Hasil penelitian ini } \\
\text { meggunakan software } \\
\text { macromedia } \\
\text { dreamweavear untuk } \\
\text { bahasa pemograman } \\
\text { PHP, dan database } \\
\text { Mariadb sebagai tempat } \\
\text { penyimpanan data yang } \\
\text { akan digunakan. } \\
\text { Metode pengembangan } \\
\text { sistem yang digunakan } \\
\text { dalam penelitian ini } \\
\text { metode waterfall }\end{array}$ \\
\hline & & $\begin{array}{l}\text { 2) Pengembangan } \\
\text { Sistem Informasi } \\
\text { Retensi Rekam } \\
\text { Medis Di Rumah } \\
\text { Sakit Dustira } \\
\text { Cimahi (Ardi } \\
\text { Taryanto, 2019) }\end{array}$ & $\begin{array}{l}\text { Ardi } \\
\text { Taryanto } \\
\text { dan Lilis } \\
\text { Nur } \\
\text { Handaya } \\
\text { ni }\end{array}$ & $\begin{array}{l}\text { Metode peangkat lunak } \\
\text { yang digunakan dalam } \\
\text { pengembangan sistem } \\
\text { informasi retensi rekam } \\
\text { medis ini adalah } \\
\text { Waterfall, dengan } \\
\text { menggunakan tahapan } \\
\text { perancangan sistem, } \\
\text { analisis, pemograman, } \\
\text { pengujian, } \\
\text { pengoprasian dan } \\
\text { pemeliharaan. }\end{array}$ \\
\hline
\end{tabular}

Pada penelitian ini menampilkan gamba dari diagram konteks, Data Flow Diagram (DFD) level 0 sistem retensi, dan perancangan database dengan menggunakan entry relationship diagram dan relasi tebel. Juga menampilkan hasil uji coba terhadap aplikasi

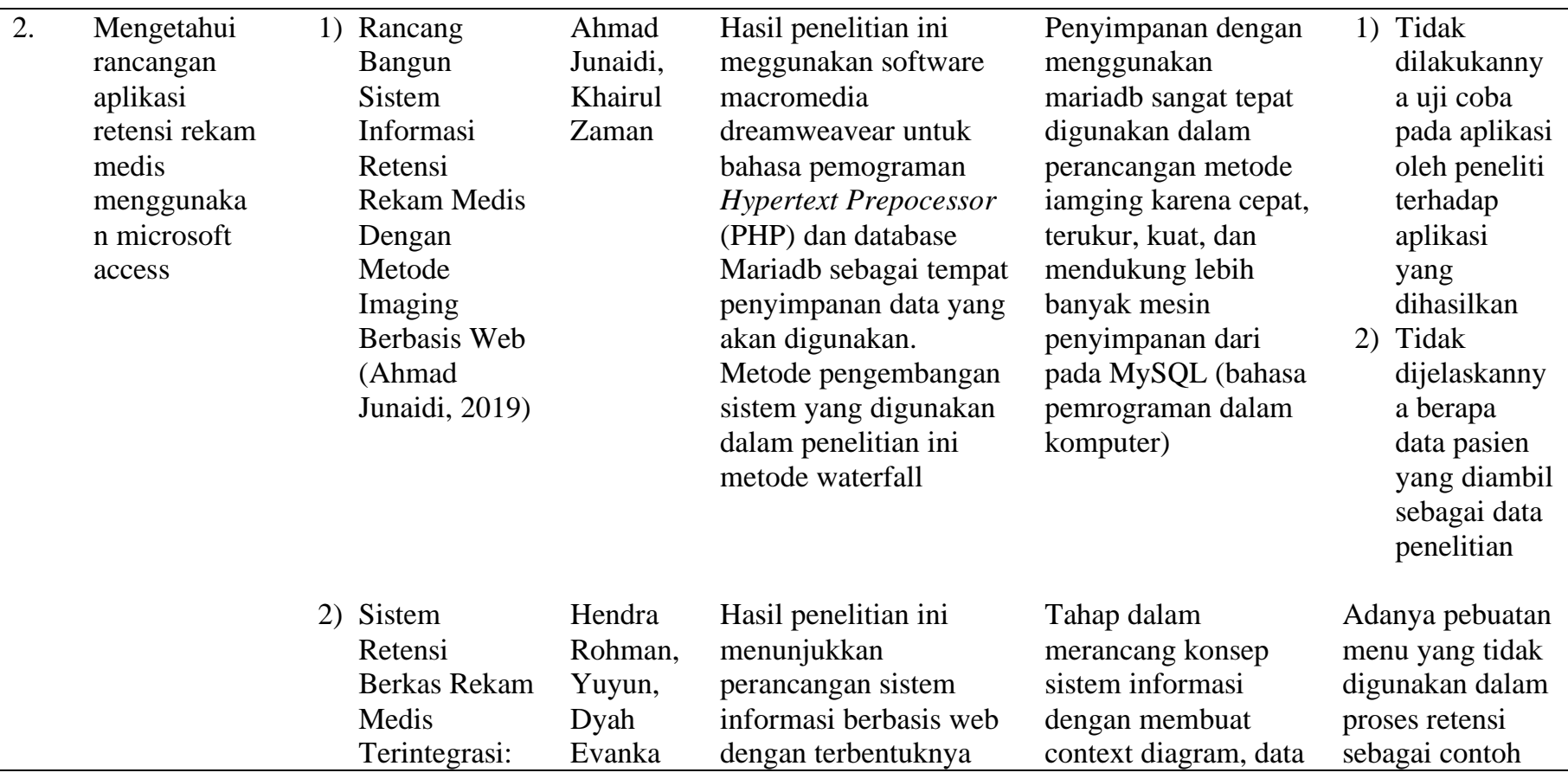




$\begin{array}{ll}\text { Perancangan } & \text { Nur } \\ \text { Sistem } & \text { Ikhsani } \\ \text { Informasi } & \\ \text { Berbasis Web } & \\ \text { Di Klinik } & \\ \text { Pratama } & \\ \text { (Rohman et } & \\ \text { al., 2019) } & \end{array}$

menu retensi dengan metode prototyping, dengan menggunakan text editorial visual studio code dan rancangan antarmuka dengan bantuan framework bootstrap, sistem menggunakan farmework laravel, dan basis data menggunakan mysql.

\section{ISSN 2623-1573 (Print)}

aliran diagnram, use case, activity diagram dan relasi antar tabel

yaitu tampilan menu pasien yang digunakan untuk mencetak kartu berobat pasien, sedangkan berkas yang akan diretensi segera dimusnahkan.

\begin{tabular}{lll}
\hline Efektivitas & Pengembangan & A \\
dari Aplikasi & Sistem Informasi & T \\
retensi rekam & Retensi Rekam & L \\
medis & Medis Di Rumah & Sakit Dustira \\
& Cimahi (Ardi & \\
& Taryanto, 2019)
\end{tabular}

Ardi
Taryanto,
Lilis Nur
Handaya
ni

Hasil dati uji efektifitas

aplikasi yaitu:

1) Apabila user name dan password sesuai dan bisa masuk maka hasilnya sukses

2) Apabila data kosong maka tidak akan bisa masuk kama akan muncul pesan untuk memasukan user name dan password maka hasilnya sukses

3) Apabila data tidak terdaftar dan akan muncuk pesan untuk memasukan user name dan pasword maka hasilnya sukses.
1) Peneliti dapat menampilkan pengujian sistem dari aplikasi yang dirancang sehingga pembaca dapat melihat efisien dan efektivitasnya suatu aplikasi yang dibutuhkan oleh pengguna

2) Penggunaan metode waterfall sangat sesuai dengan aplikasi retensi, karena melakukan pendekatan pada pengembangan perangkat lunak secara sistematik dan sekuensial, sehinggap dapat menilai tingkat efektifitas dari aplikasi

\section{PEMBAHASAN}

Dalam melakukan telaah artikel, dapat dilakukan dengan menggunakan teknik literature review antara lain menentukan kesamaannya (compare), menentukan ketidaksamaannya (contrast), berikan pandangan (critize), bandingkan (synthesize), dan ringkasan (summarize).

\section{Kesamaannya (Compare)}

Berdasarkan beberapa literatur yang telah di analisis, terdapat kesamaan mendasar terhadap penyebab dilakukannya perancangan aplikasi retensi. Kesamaan dilihat dari artikel yang berjudul "Rancang Bangun Sistem Informasi Retensi Rekam Medis dengan Metode Imaging Bebasis Web" yang ditulis oleh Ahmad Junaidi dan Khairul Zaman pada tahun 2019 dengan artikel yang berjudul "Sistem Retensi Berkas Rekam Medis Terintegrasi: Perancangan Sistem Informasi Berbasis Web di Klinik Pratama" yang ditulis oleh Hendra Rohman, dkk ada tahun 2019, dimana kesamaan dilihar dari elemen data yang digunakan yaitu dimulai dari Context Diagram, Data Flow Diagram (DFD) level 0 dan Entity Relationship Diagram (ERD) pada sistem aplikasi retesi rekam medis. 
Pada artikel Ahmad Junaidi (2019) dan Hendra Rohman (2019) juga memiliki kesamaan pada rancangan aplikasi retensi rekam medis yang dilihat dari tampilan menu-menu yang dihasilkan. Beberapa contoh menu-menu yang di dalam aplikasi yang memiliki kesamaan antara menu login, menu utama, menu retensi dan menu laporan.

\section{Ketidaksamanaan (Contrast)}

Dari beberapa artikel tersebut juga ditemukan ketidaksamaan antara satu sama lain. Ketidaksamaan dilihat dari artikel yang berjudul "Rancang Bangun Sistem Informasi Retensi Rekam Medis Dengan Metode Imaging Bebasis Web" yang ditulis oleh Ahmad Junaidi dan Khairul Zaman pada tahun 2019 dengan artikel yang berjudul "Sistem Retensi Berkas Rekam Medis Terintegrasi: Perancangan Sistem Informasi Berbasis Web Di Klinik Pratama" yang ditulis oleh Hendra Rohman dkk ada tahun 2019 dimana ketidaksamaan sudah jelas terlihat pada judul dimana metode yang digunakan berbeda, artikel yang di tulis oleh Ahmad Junaidi dan Khairul Zaman menggunakan metode imaging berbasis web, sedangkan artikel yang ditulis oleh Hendra Rohman dkk metode yang digunakan hanya berbasis web (Rohman et al., 2019). Dikarenakan perancangan ada yang menggunakan basis web dan ada juga yang menggunakan imaging berbasis web. Sehingga sub menu yang dihasilkan oleh setiap aplikasi berbeda. Artinya metode yang digunakan dalam merancang dan mengembangkan aplikasi retensi tidak hanya berpatokan kepada satu metode saja hal ini tergantung terhadap kebutuhan dari pemakan/user aplikasi (Haris, 2012).

Pada artikel (Junaidi, A., Zaman, 2019) juga memiliki ketidaksamaan dalam perancangan aplikasi rekam medis karena ada beberapa menu yang dibuat dalam suatu aplikasi tidak terdapat dalam aplikasi lainnya. Contoh menu-menu yang tidak ada antara aplikasi yang satu dengan yang lainnya menu poliklinik, menu farmasi, menu diagnosa, menu tindakan, menu dokter, menu pemeriksaan dan menu pembayaran.

\section{Pandangan (Critize)}

Dari analisis dan telaah beberapa artikel, perancangan menggunkan elemen data yang sama yaitu Context Diagram, Data Flow Diagram (DFD) level 0 dan Entity Relationship Diagram (ERD) (Arfyanti, Harianto, \& Pradifta, 2018). Namun menggunakan metode yang berbeda, sehingga dari hal tersebut juga menghasilkan menu-menu yang berbeda pada setiap aplikasi, menu yang dihasilkan tersebut sesuai dengan kebutuhan rumah sakit/user dalam melakukan retensi berkas rekam medis. Serta aplikasi perlu dikembangkan untuk mendapatkan afektivitas dalam pemakaian aplikasi tersebut. Namun dari dipandang dari segi keguaannya, aplikasi yang dirancang dengan metode yang berbeda memiliki kegunaan yang sama yaitu membantu petugas dalam memisahkan berkas rekam medis inaktif dan aktif.

\section{Bandingkan (Synthesize)}

Perancangan adalah tahap setelah analisa dari siklus pengembangan sistem yang dapat berupa penggambaran, perancangan dan pembuatan sketsa atau peraturan dari beberapa elemen yang terpisah ke dalam satu kesatuan yang utuh dan berfungsi, termasuk menyangkut dari komponen-komponen perangkat lunak dan perangkat keras dari suatu sistem (Jogiyanto, 2005). Dari ketiga artikel yang telah dianalisis, dalam penelitian yang dilakukan oleh (Junaidi, A., Zaman, 2019) sejalan dengan teori yang di paparkan, dimana dalam perancanga aplikasi retensi juga dilakukan penggambaran dan pembuatan skema serta elemen data yang akan digunakan dalam merancang aplikasi retensi dalam bentuk komponen perangkat lunak seperti Diagram Kontext, Data Flow Diagram (DFD) Level 0, Entity Relationship Diagram (ERD) dan bahasa pemograman PHP MySQL dan perangkat 
keras seperti komputer, CPU, dan mesin scan (Nisa Srimayarti \& Siregar, 2019).

Perancangan aplikasi yang dilakukan menghasilkan menu-menu yang juga akan membantu dalam melakukan proses retensi, namun setiap aplikasi memiliki menu-menu yang berbeda, hal ini tergantung kepada kebutuhan user dalam menggunakan aplikasi tersebut. Untuk itu dilakukannya uji efektivitas agar hasil perancangan lebih maksimal dan mengetahui kekurangan yang harus diperbaiki didalam sebuah aplikasi tersebut.

\section{Ringkasan (Summarize)}

Perancangan aplikasi retensi merupakan Suatu kegiatan untuk merancang atau membuat dan membentuk pola-pola tertentu baru yang dapat menyelesaikan masalah-masalah yang dihadapi oleh tenaga rekam medis dalam melakukan pemusahan rekam medis terutama dalam proses retensi (pemisahan) berkas aktif dengan inaktif. Perancanan aplikasi retensi dilakukan dengan tahap-tahap yang telah dianalisa sebelumnya, baik itu dimulai dari elemen data hingga komponen-komponen yang akan digunakan dalam aplikasi. Pada 3 artikel yang telah diteliti ditemukan pembuatan program yang disusun sesuai dengan bertahap, mulai dari kontext diagram, DFD, ERD sampai dengan bahasa pemograman yang akan digunakan dalam menjalankan suatu aplikasi.

Perancangan aplikasi juga menghasilkan menu-menu yang akan digunakan dalam proses retensi, namun setiap menu-menu dalam aplikasi berbedabeda. Hal ini tergantung kebutuhan rumah sakit/user yang akan menggunkan aplikasi tersebut. Namun ada beberapa menu yang memiliki kesamaan menu secara umum yaitu menu login, menu utama, menu retensi dan menu pelaporan. Hasil perancangan juga harus dilakukan uji efektivitas terhadap aplikasi dengan menggunakan beberapa uji terhadap menumenu yang dihasilkan, mulai dari menu login sampai dengan menu pelaporan. Hal ini bergunak untuk pengembangan pada aplikasi agar tidak terjadi kendala dalam melakukan retensi berkas rekam medis (Wirayudha, Pribadi, \& Arif, 2017), (Nisa Srimayarti \& Siregar, 2019).

\section{KESIMPULAN}

Berdasarkan review dari 3 literatur yang dilakukan mengenai Aplikasi Retensi Rekam Medis Menggunakan Microsoft Acces tahun 2020 diperoleh kesimpulan bahwa tahap perancangan dalam konsep sistem informasi dengan membuat menggunakan elemen data seperti context diagram, data aliran diagram (DFD dan ERD), user case, activity dan relasi antar tabel. Perancangan aplikasi retensi dibuat dengan berbagai metode seperti metode berbasis web dan bebasis imaging web dengan menu-menu yang sesuai dengan kebutuhan rumah sakit/user, dan efektivitas terhadap aplikasi harus dilakukan untuk mengetahui kendala yang terdapat pada aplikasi, hal ini berguna sebagai pengembangan aplikasi untuk meminimalisir kesalahan yang terjadi daam proses retensi.

\section{UCAPAN TERIMAKASIH}

Penulis mengucapkan terima kasih kepada STIKES Dharma Landbouw Padang dan rekan-rekan penulis khususnya Prodi S1 Administrasi Rumah Sakit atas dukungan yang diberikan, sehingga artikel ini dapat terselesaikan.

\section{DAFTAR PUSTAKA}

Ahmad Junaidi, K. Z. (2019). Rancang Bangun Sistem Informasi Retensi Rekam Medis dengan Metode Imaging Berbasis Web. Intecoms: Journal of Information Technology and Computer Science, 2, 33-39. https://doi.org/https://doi.org/10.31539 /intecoms.v2il.753

Ardi Taryanto, L. N. H. (2019). Pengembangan Sistem Informasi 
Retensi Rekam Medis di Rumah Sakit Dustira Cimahi. Jurnal E-KOMTEK (Elektro-Komputer-Teknik), 3(2), 6270.

Arfyanti, I., Harianto, K., \& Pradifta, D. R. (2018). Sistem Informasi Rekam Medis Berbasis Jaringan Pada Puskesmas Loa Bakung Menggunakan Asp.Net 3,5. Sebatik, 11(1), 7-12. https://doi.org/10.46984/sebatik.v11i1. 94

Depkes RI. Pedoman Penyelenggaraan Prosedur Rekam Medis Rumah Sakit di Indonesia (2006). Indonesia.

Devita, S. (2015). Tinjauan Pelaksanaan Retensi Dokumen Rekam Medis Aktif Di Bagian Filing Rumah Sakit Bhaki Wira Tamtama Semarang. Retrieved from

https://core.ac.uk/display/35382876

Haris, M. S. (2012). Prosiding Seminar Rekam Medik Dan Informasi Kesehatan Perancangan Dan Pembuatan Aplikasi Retensi Berkas Rekam Medis di RSD Balung Jember Prosiding Seminar Rekam Medik Dan Informasi Kesehatan. Prosiding Seminar Rekam Medik Dan Informasi Kesehatan, 23-31.

Jogiyanto. (2005). Analisis dan Desain Sistem Informasi. Yogyakarta: Andi.

Junaidi, A., Zaman, K. (2019). Metode Imaging Berbasis Web Designing a Medical Record Retention Information System With Web-Based Imaging Method. UPI YPTK, 33-39.

Kemenkes RI. Undang-undang RI Nomor 44 Tahun 2009 tentang Rumah Sakit (2009). Indonesia. Retrieved from http://dkk.balikpapan.go.id/assets/files/ 1.UU44-09-RS_.pdf

Mujiati, H., \& S. (2014). Sistem Informasi Dan Implementasinya Teori Dan Konsep Sistem Informasi Disertai Berbagai Contoh Pratiknya Menggunakan Perangkat Lunak Open Source. Indonesian Jurnal on Computer Science, 1-6. Retrieved from

https://doi.org/10.3112/SPEED.V12I1.

\section{1}

Nina Rahmadiliyani, F. (2018). Kerahasiaan Rekam Medis di Rumah Sakit Aveciena Medika Martapura. Manajemen Informasi Kesehatan Indonesia, 6(2). Retrieved from https://jmiki.aptirmik.or.id/index.php/j miki/article/view/189

Nisa Srimayarti, B., \& Siregar, K. N. (2019). Prototyping Personal Health Records for Type 2 Diabetes Mellitus Prevention. Indian Journal of Public Health Research and Development, 10(11), 1862-1867. https://doi.org/10.5958/09765506.2019 .03824 .5

Pepres RI Nomor 11. Informasi dan Transaksi Elektronik (2008). Retrieved from

https://www.kpk.go.id/images/pdf/uu pip/UU_ITE no 11 Th 2008.pdf

Permenkes RI. Nomor 269/MENKES/PER/III2008 tentang Rekam Medis (2008). Indonesia. Retrieved from https://www.academia.edu/36056592/P ERMENKES_269_MENKES_PER_II I_2008_TENTANG_REKAM_MEDIS

Rohman, H., Evanka, D., \& Ikhsani, N. (2019). Sistem Retensi Berkas Rekam Medis Terintegrasi: Perancangan Sistem Informasi Berbasis Web di Klinik Pratama. Jurnal Manajemen Informasi Dan Administrasi Kesehatan (JMIAKO, 02(November), 10-22. Retrieved from jmiakmedrec@gmail.com

Rufiantum. (2007). Tinjauan Alur Prosedur Pemusnahan Dokumen Rekam Medis.

Saraswati, D. (2015). Tinjauan Pelaksanaan Retensi Dokumen Rekam Medis Aktif di Bagian Filing Rumah Sakit Bhaki Wira Tamtama Semarang Tahun 2015. Wirayudha, S., Pribadi, T. W., \& Arif, S. (2017). Perancangan Aplikasi Berbasis Android Untuk Aktivitas Manajemen Material Galangan Kapal Baru. Jurnal Teknik ITS, 6(2). https://doi.org/10.12962/j23373539.v6i 2.24119 